\title{
Social Sensitivity in The Interaction of The Online Teaching Profession Learning Community in Indonesia
}

\author{
Edhy Rustan ${ }^{1}$, Muh Irfan Hasanuddin ${ }^{2}$, Andi Muhammad Ajiegoena ${ }^{3}$ \\ \{edhy_rustan@iainpalopo.ac.id ${ }^{1}$,irfanajih@gmail.com², ajiegoena@iainpalopo.ac.id\} \\ Islamic State Institute of Palopo ${ }^{1,2,3}$ \\ Jl. Agatis Balandai, Palopo City, Indonesia, 91914
}

\begin{abstract}
The purpose of this study is to explore the challenges of the online learning community in Indonesia, social sensitivity in online learning, and eliminate the instructional online system that is needed. Data collection was carried out through a virtual deepening response to the 2019 PAI online learning community teachers in Indonesia. The results obtained showed the advantages and disadvantages of the use of new social space in the interaction among the student community. Social sensitivity such as empathy, respect, mutual interaction, and social care built from togetherness in conventional learning is changing. The interactions created by online learning present a technical sensitivity to the use of software, features, symbols, and icons. Furthermore, this interaction has brought about independence and discipline. The instructional online system design required is instructional content that is integrated with social experience in everyday life.
\end{abstract}

Keywords: Social Sensitivity; Interaction; Online Learning Community.

\section{Introduction}

The $5^{\text {th }}$ Industrial revolution's era is basically a continuation of the previous $4^{\text {th }}$ industrial revolution which have always changed the world significantly. This era promotes convenience for humans through the use of technology. This development certainly has an impact on all fields including education. Online learning is one of the uses of technology in the field of education, such as Teacher Professional Education Training Program (PPG). The implementation of PPG is the implication of Government Regulation Number 74 of 2008 concerning about the teachers' obligation to have academic qualifications, competencies, and educator certificates. This teacher professional program is held for a year through an online education.

Online learning comes with a number of advantages, including the ease of information access by students that can be done anywhere and anytime [1], freedom to share opinion and students are required to be more active and think critically [2]. Online learning is individual so it requires students to be able to be independent and disciplined [3]. However, behind these advantages, there are also some negative impacts that occur due to online learning, namely the difficulty of learning access for students in areas without the internet networks and the reduction of social sensitivity which is regarded as one pivotal aspect in learning process.

The reduction of social aspect in the online learning has become a critical issue to consider. This aspect includes social sensitivity which refers to the condition of a student in a community group who understands, feels and provides solutions to various social problems and phenomena 
existed around him [4]. Various factors influence the social context in online learning, including effective dialogue, well-structured interaction, ease of use, and transparency in computermediated interactions [5]. Various forms of social sensitivity such as empathy, tolerance, social care, etc. are beginning to erode and dim in the context of online learning. Empathy refers to the ability to deduce a person's feelings and to feel what someone feels. Empathy relies heavily on verbal cues in face to face so that empathy in online interactions has shifted to different contexts [6]. Social care is influenced by a sense of togetherness between students [7]. The lack of a sense of togetherness among students is due to the absence of direct interaction [3], [8].

Social care that occurs in online learning is difficult to describe [9]. Since the concern leads more focus to technical problems, such as using devices, features, networks and others. Another aspect that also changes is about tolerance. While, students who get ill or permission in the conventional system will get a time extension and tolerance in collecting their assignments, such condition is different in the online education. This causes social sensitivity, especially the nature of tolerance, which is no longer present and tolerated anymore in this online learning model, affecting students who have low ability to feel isolated [3].

In order to respond to various weaknesses related to social sensitivity in online learning, the need for learning quality and continual development is remarkably indispensable. The teacher, for example is required to begin with an introduction of each member at the beginning in the meeting, conduct online discussions in groups, appropriate changes in teaching styles and learning development stages [2], [9], [10]. The use of social communication strategies also plays an important role in building an interactive communication that can foster a desire to share awareness among online learners [9], [11]. In addition, giving enthusiasm, motivation, a conducive discussion environment, building trust, timely feedback and responding to questions and remaining respectful are also able to present a side of social awareness in online learning [9]. Furthermore, in order to instill empathy in the learner, good deeds and empathy have to integrated to a curriculum design so that students can still learn how to be able to empathize others even though only through online learning [12], [13].

The purpose of this study is to explore the advantages and challenges of PPG online learning at IAIN Palopo, the relevance of online learning in era 5.0, and the online instructional design system needed to stimulate social sensitivity in the era of industrial revolution 5.0.

\section{Research Method}

The subject of this study was the PAI's teacher at professional online learning community in Indonesia in 2019. Respondents were randomly selected from a total of 2995 students and 1369 lecturers held by 36 higher teacher training institutions under the Ministry of Religious Affaris's admnistration in Indonesia. Data collection was done through the deepening of the virtual response to the online learning community teaching profession program in Indonesia at https://ppg.siagapendis.com/. To get the reliable a maximum response, implied questions are internalized in the discussion forum at the last meeting of learning. This research used pedagogic, psychological, and social theoretical approaches. The data analysis technique used the interactive model Miles and Huberman which consists of four stages; data collection, data reduction, data presentation, and conclusion with verification. 


\section{Result and Discussion}

\subsection{The challenge of the online PPG learning community in Indonesia}

The idea of renewal carried by the concept of the 5 th industrial revolution as its criticism of the concept of 4.0 is the value of humanism or in other words revitalizing the role of humans in the digital ecosystem. This idea has become a widespread criticism of the PPG online learning community. As data shows, of the 45 students who expressed their opinions, there were $97 \%$ who experienced problems as a result of an internet connection that was less stable and tended to be slow. Such related problems for internet connection networks were discussed 67 times. This reflects significantly the main problem in online learning, especially in Indonesia.

Online learning was created to facilitate participants to follow the learning process wherever they are. Some benefits of this type of learning can stimulate the participation to learn properly. First. This online learning can save time which allow the participant to adjust and choose their time. The flexible time offered by the online learning has opened a great opportunity for the participants with over loaded duties at home, family and professional duties at schools. Second, this learning model has opened a greater space from them to learn wherever they are. The participants have enough time to work in an open, flexible learning environment where they may participate in a collaborative group or learn individually. Third, this learning process has an efficiency in accommodation, transportation costs, and energy. In general, the learning process is often conducted in the heart of city which enforce the students to move to the city and commute every day. This condition really consumes a financial budget for an accommodation living in the city, time and physical energy. Therefore, the existence of online learning is to facilitate the participants to obtain knowledge from reliable instructors from various places. As long as this learning is supported by the internet network system network and server, the learning process will work at all.

Uneven access to the internet networks in every place forces the participants to struggle hard to attend every online learning session every day. More importantly for the participants who live in rural areas, or even assigned as teachers in remote areas without any access to the internet and electricity networks, this situation may exacerbate the learning process. As a result, the participants attending online learning should leave their hometown, students' assignments are possibly slower than scheduled, there are even students who do not have time to take formative tests. This condition was experienced by several other participants, "if I am given a choice, then I chose full face-to-face learning, so I do not need to catch up with the internet network and the time that took a considerable distance" (Informant PU).

In addition to the internet network, time and opportunity are the second most conversation after the network. The content reached 28 times in the discussion. For example, the expressions of "no time off", "No permit, sickness or other reasons reflect how time become an issue in online education. In addition, based on respondents' response, there was no time to take a nap and could not compromise with time. That is a lack of feeling forced, but at the same times an advantage, because with these conditions, students are educated to be more disciplined. While such condition might be considered as a difficult challenge, they are active disciplines in doing self-study because of scheduled tasks in the use of time.

Another positive effect that arise in online learning is creativity and ability of students to operate IT better than before by actively following the learning process. They become more proficient in operating a Laptop. "We are forced to know ICT" (Informant MI). So, it can be said that online learning provides new knowledge about the optimal use of media. They feel that 
they have different experiences since they were usually taught and learned in the ways of faceto-face education.

Complete features are very influential on optimal interaction. Based on the results of the response, information was obtained that students were more flexible in asking through the features provided (Informant MI). However, based on the results of observations on the system used, the results obtained are that it is necessary to add features that can facilitate and present the social presence of the interactions produced. The online learning system used is not equipped with communication features with lecturers with sound or video. So, the Lecturer does not know what is happening to the participants in the learning process.

\subsection{Social sensitivity in Online Learning IR 5.0}

The implementation of online learning can form new communities, add new friends and relatives, and make it easier to establish more intimate friendships. Nevertheless, the absence of face to face communication in understanding the character among them experiences difficulties. Other things can also happen such as the possibility of identity falsification due to the ease access for those who IT's practitioner and the misuse of IT (Informant PU). The problem was regarded as a result of the interactions between the lecturers and participants of the PPG and among other participants. So, "the familiarity created was less than perfect" (JA 2019). Further, "even though the participants could communicate with lecturers or friends from other regions, even so they could not understand each other's character either from friends or lecturers. As a result of this, social sensitivity is reduced" (Informant HA).

Each participant has his own conditions, responsibility, social burden and culture where each of them also requires a friendly system to social problems. Just take an example, Martin with her pregnancy has to attend in PPG online at the same time has to teach at school. Such conditions can engender participants become vulnerable to a range of stress and personal range.

The previous presentation reviews various critics of online learning along with some input as a support to improve material especially in the online PPG learning model. Apart from that of course, online learning of the PPG program model also has several advantages including the objectivity of learning outcomes assessment. As expressed by one of the respondents, "this program facilitates the process of receiving material much easier and the assessment is more transparent" (IJ 2019).The value of transparency and objectivity is very relevant for the PPG online learning model considering that the context of this learning program is basically training. The transparency and objective assessment are the translation of the PAP assessment system or benchmark reference assessment. So, the assessment of the learning achievement of a PPG participant depends on how much the benchmark score is. This perspective provides an overview of the graduation standards of a teacher who has followed the PPG and who has not participated in it. Through the online learning model, the objectivity in assessment is supported by the use of IT media.

In online learning on the PPG program, community interaction is well-documented. Here, students can look back on the interactions carried out in the system. Likewise, learning materials are stored well in the system which enable them reading learning material repeatedly and store it on a computer. The principle of online learning with learning independence, flexibility of time and virtual place requires documentation of good learning. Because of these two principles, each student basically can regulate the speed and rhythm of their learning according to their conditions, potential and learning style. Therefore, online learning can be considered to respond to their differences characters in different ways more importantly in the dimensions of learning independence primarily at the speed of learning. 


\subsection{Online System Instructional Design is Required}

The analysis and identification of students' learning character are one of the development stages of learning design which are also an integral part of developing online learning system. At this stage, a learning designer is required to understand the learning character of learning target. This is necessary considering that each individual has the potential and diversity related to students' learning interest and styles, and intelligence. In turn, the urgency about analyzing student characters is an assumption to determine learning objectives, types of activities, learning materials to evaluation techniques. If so, similar to face-to-face learning models, the online learning model in such a way should reflect the principle of accommodating students' differences in character which contribute to differences in learning needs. But once again, the limitations of virtual space have become a barrier. As the respondent said, "I am a person who is easy to understand something with a direct explanation compared to reading material, so that in understanding the subjects I sometimes still need an explanation from a competent person. meaning that learning for me will be meaningful in face-to-face activities" (Informant HJ). The important point raised by the respondents is not about the difficulty of learning difficulties in online models that do present information in writing and not verbal / face-to-face but rather reflect the fact that there are learning style needs that have not been met by online learning models. So, innovation of various types is needed to accommodate a variety of learning activities. For example, the use of features and icons that can improve the social presence of students. Humanistic and social interaction are transformed in the form of more meaningful semiotic symbols.

On the other hand, this fact shows the lack of interaction of humanism during the online learning process where in face-to-face learning such obstacles will be immediately responded by the learner and teacher. The crucial point is the need for a formative evaluation space during the learning process. During this period of this research, the researchers followed some online learning applications including PPG online learning applications. The online website generally consisted of attendance features, messages, material-content, material discussion space, assignments to summative tests. These features also limit the types of learning activities that specifically have not provided communication space in the formative evaluation function. Thus, to provide a deeper nuance of humanism in the online learning system, a special discussion room is needed to give a roar to learn and teachers in diagnosing learning difficulties and obstacles that may be experienced by students during the learning process.

In addition to the addition of features, the characterization of more humanistic online learning can also be realized through the development of content and learning material based on an analysis and case studies. Such content can provide a more contextual learning experience than just exposure to material that tends to be conceptual. Through content analysis of cases that integrated social experience in everyday life, learning can be directed to the learning model of transfer of value rather than the transfer of knowledge. In this regard, learning process is designed to more meaningful and contextualized by connecting the content of the subject to real life of the students or participants. The use of a number of real examples from their experiences is considered significant.

The character of online learning that emphasizes learning independence is on the other hand related to learning honesty. With the initial intention of providing learning facilities without depending on time and place, the independence of students always to regulate the rhythm of their learning activities is a significant factor. But with this nature, the control by admin along with tutors on student learning activities is low. It is not impossible that the online learning model is actually counterproductive, especially if learning independence is not supported by 
responsiveness and honesty. As the respondent's comment stated "the weakness of this learning model is the large number of data falsification, the absence of non-verbal communication, no direct physical contact and communication" (Informant AI). Verification and validation toward student activities in online PPG learning is felt to be still low. Whereas, the output of the PPG program is increasing the capacity and competence of teachers which may be achieved if the online learning activities are actually dealt with by participants using substitute participants (jockeys). In addition, dishonesty can also be seen in the quality of discussion and student resume assignments that do show the similarities with one another. This is including the use of online learning resources without mentioning the source.

Dishonesty in the terms of misusing jockey is a form of violation that cannot be tolerated. There is no room for debate regarding the validity of the form of this lack. But the use of online learning resources and plagiarism behavior for some online learning practitioners and experts is debatable. For example, about the limitation of the online learning sources quote or even the most important thing is the originality of comments, answers to the task of learning which is the most important. Apart from the theme of the debate, fraudulent practices in online learning can be reduced and alleviate by maximizing the verification and validation process for each participant, both students and learners. Because it is possible that cheating and dishonesty practices can be carried out by learners. Every fraud and dishonesty during the learning process will have an impact on the accumulation of learning outcomes leading to the decrease of graduates' quality.

The response to learners' interest in the overall PPG online learning activities is quite low. This has been influenced by at least two things; a long time/duration and a monotonous learning activity. As quoted by a respondent's suggestion "... We only recommend here that the period of PPG is not last too long more than 3 months" (Informant MU). The response indicates that the student was not comfortable in the learning community. This was explicitly reinforced by respondents (Informant AC) who argued that PPG learning was quite saturating. The two comments at least represented the response of most respondents to the regulation of learning burdens in the PPG curriculum. This curriculum was considered too heavy and the packaging of learning activities tended to be monotonous. Ideally, good learning may refer to learning with the ability to provide a positive experience for students. Positive learning experiences to support the process of internalizing new values, knowledge, and skills in accordance with the students 'initial conditions or students' needs. In other words, good learning through positive experiences will support optimal learning outcomes. The meaning of positive experience is the learning process that must be fun, activate and to encourage students to be actively involved during the learning process, and not vice versa to become passive learners, less interested to be indifferent. The condition of learning with a positive learning experience is known as meaningful learning.

Online learning models should create meaningful learning for the students. Moreover, there is a considering fact that the burden of the PPG curriculum must meet certain standards of load in accordance with the rules and policies of teacher professional development. This causes the duration of online learning to be sufficient for 3 months instead of 6 months of the overall PPG activities. To continue maintaining the attention and an interest of the participants, a more diverse variety of learning are needed, at least starting with a more diverse learning activities and flexible schedule. 


\section{Conclusion}

The obtained results show that there are new social spaces in the interaction of the learning community. Social sensitivity such as empathy, respect feelings, tolerance, and social care formed from togetherness in conventional learning are changing. The interactions created by online learning have brought about a feeling of sensitivity to the technical use of software, features, and applications. In addition, this interaction breeds an independence and discipline. It is better for the teachers to provide an instructional content integrated with a social experience in everyday life. Consequently, it is necessary to pay attention to the character of students, the use of features and icons that can increase the attractiveness and social presence of the students

\section{References}

[1] Ke, F and Hoadley, C.:Evaluating online learning communities," Educ. Tech Res. Dev, Vol. 57, pp. 487-510 (2009)

[2] Auyeung, L. A. I. H.: Building A Collaborative Online Learning Community : A Case Study In Hong Kong, J. Educ. Comput. Res., Vol. 31, no. 2, pp. 119-136 (2004)

[3] Rovai, A. P and Jordan, H. M.: "Blended Learning and Sense of Community: A comparative analysis with traditional and fully online graduate courses," Int. Rev. Res. Open Distance Learn., Vol. 5, no. 2, pp. 1-13 (2004)

[4] Chandra, K and Anggraini, S.:Penerapan Model Pembelajaran Inkuiri Terbimbing Untuk Meningkatkan Kepekaan Sosial Siswa Dalam Pembelajaran IPS Di MTs Negeri Lamongan," Akademika, Vol. 9, no. 2, pp. 261-276 (2015)

[5] Dow, M J.:Implications of Social Presence for Online Learning: A Case Study of MLS Students, J. Educ. Libr. Inf. Sci., Vol. 49, no. 4, pp. 231-242 (2008)

[6] J. Feng, J., Lazar, J and Preece, J.: Relationship Empathy and Online Interpersonal Trust : A fragile Relationship, Behav. Inf. Technol., Vol. 23, no. 2, pp. 97-106 (2007)

[7] Oztok, M and Brett, C.: Social Presence and Online Learning: A Review of Research, Int. J. E-Learning Distance Educ. Vol. 25, no. 3 (2011)

[8] Finch, A "Critical incidents and language learning: Sensitivity to initial conditions," System, Vol. 38, no. 3, pp. 422-431 (2010)

[9] Plante, K and Asselin, M. E. "Best Practices for Creating Social Presence and Caring Behaviors Online, pp. 219-224 (2010)

[10] Rovai, V.: "Building Sense of Community at a Distance," Int. Rev. Res. Open Distance Learn., Vol. 3, no. 1, pp. 1-16 (2002)

[11] Tu, C and Mcisaac, M.: The Relationship of Social Presence and Interaction in Online Classes The Relationship of Social Presence and Interaction in, Am. J. Distance Educ., Vol. 16, no. 3, pp. 131-150 (2002)

[12] Hall, C.: The Place of Empathy in Social Constructionist Approaches to Online Tutor Training in Higher Education," Malaysian J. Distance Educ., Vol. 10, no. 2, pp. 33-50 (2008)

[13] Durlak, J. A. Weissberg, R. P, Dymnicki, A. B and Taylor, R. D.: The Impact of Enhancing Students' Social and Emotional Learning: A Meta-Analysis of SchoolBased Universal Interventions, Child Dev., vol. 82, no. 1, pp. 405-432 (2011) 